\title{
PILOTED SIMULATION STUDY OF TWO TILT-WING CONTROL CONCEPTS
}

\author{
LOURDES G. BIRCKELBAW AND LLOYD D. CORLISS
}

\author{
Ames Research Center \\ Moffett Field, California
}

\begin{abstract}
Summary
A two-phase piloted simulation study was conducted to investigate alternative wing and flap controls for tilt-wing aircraft. The initial phase of the study compared the flying qualities of both a conventional (programmed) flap and an innovative geared flap. The second phase of the study introduced an alternate method of pilot control for the geared flap and further studied the flying qualities of the programmed flap, and two geared flap configurations. In general, the pilot ratings showed little variation between the programmed flap and the geared flap control concepts. Some differences between the two concepts were noticed and are discussed in this paper. The addition of pitch attitude stabilization in the second phase of the study greatly enhanced the aircraft flying qualities. This paper describes the simulated tilt-wing aircraft and the flap control concepts, and presents the results of both phases of the simulation study.
\end{abstract}

\section{Introduction}

Tilt-wing aircraft are a viable choice for vertical and short takeoff and landing (V/STOL) transports and other smaller V/STOL aircraft, because the tilt-wing concept lends itself well to reasonable efficiency in hover and to very good efficiency in cruise flight. A good technology base for tilt-wing aircraft exists. The first tilt-wing aircraft to transition from hover to forward flight was the Vertol VZ-2 in 1958. Other flight article tilt-wing aircraft included the Hiller X-18 (1958-1964), the Vought-HillerRyan XC-142 (1964-1967), and the Canadair CL-84 (1965-1974). In particular, the XC-142 and the CL-84 flew military operational demonstrations.

Some significant issues associated with tilt-wing aircraft include wing buffet during decelerating or descending flight, a strong wing angle to speed dependence, wing generated pitching moments, and the requirement for a tail rotor or tail thruster to provide pitch control at low speeds and hover.

Renewed interest in tilt-wing aircraft from the military and civil communities resulted in the piloted simulation study at NASA Ames Research Center. This renewed interest includes use of tilt-wing aircraft for the U.S. Special Operations Command aircraft, the U. S. Air Force Advanced Theater Transport, NASA high speed rotorcraft studies, and proposed civil applications. A new look at tilt-wing aircraft was further motivated by advances in technologies such as propulsion, materials, and flight control systems which offer the potential to address shortfalls of previous tilt-wing aircraft.

Two piloted simulations of a transport size tilt-wing aircraft have been completed on the Ames Vertical Motion Simulator (VMS) (refs. 1-4). This paper presents the results of both simulations.

The first simulation evaluated and compared the flying qualities of two wing tilting concepts, a conventional programmed flap (where the wing is driven directly) and an innovative geared flap (where the flap serves as an aerodynamic servo to position the free-pivoting wing). The programmed flap was the control concept used by previous tilt-wing aircraft. The geared flap was first proposed by Churchill (ref. 5) and has the potential to eliminate the tail rotor or tail thruster required by previous tiltwing aircraft in hover and low speeds for pitch control; this could result in a significant reduction in aircraft weight and complexity.

The second simulation introduced several refinements, including a variation to the pilot control of the geared flap, a redefinition of the pilot evaluation tasks, and control law refinements.

The combined objectives of both simulations were to: (1) simulate a representative tilt-wing aircraft, (2) develop control laws for the programmed flap and the geared flap control concepts, (3) evaluate and compare the flying qualities of the flap control concepts, and (4) determine the feasibility of eliminating the tail rotor or tail thruster using the geared flap concept.

This paper describes the simulated tilt-wing aircraft, the flap control concepts, and the experiment design including the simulation facility and the pilot evaluation tasks of both simulations. Results of the simulations are presented, 
including flying qualities comparisons between the flap control concepts for both piloted simulations and a discussion of the tail thruster pitch control power usage by each flap configuration during the second simulation.

\section{Simulated Tilt-Wing Aircraft}

The conceptual tilt-wing aircraft of this study was a midsized V/STOL transport aircraft, sized at about two-thirds the weight of a C-130. A tail thruster was included to provide pitch control during hover and low speeds. A sketch of this conceptual aircraft is shown in figure 1 . The aircraft had an overall length of $92 \mathrm{ft}$, a gross weight of $87,000 \mathrm{lb}$, and a payload capability of $10,000 \mathrm{lb}$. It had four engines with $26 \mathrm{ft}$ diameter propellers. The thrust to weight ratio was 1.15 . The wing span was $109 \mathrm{ft}$ with an aspect ratio of 9 . The low horizontal tail was fully movable from $0^{\circ}$ to $28^{\circ}$ and was scheduled with wing incidence. The wing loading was $66 \mathrm{lb} / \mathrm{ft}^{2}$ and the disk loading was $40 \mathrm{lb} / \mathrm{ft}^{2}$.

\section{Aircraft Control Effectors}

During hover and low speed flight, longitudinal control was provided by the tail thruster and wing incidence, and pitch control was provided by the tail thruster. Pilot preference and choice of longitudinal control technique near hover was somewhat configuration dependent and will be discussed in the results of the second simulation. During conversion, the elevator, horizontal tail, and tail thruster provided pitch control. The throttle controlled altitude during hover and conversion. During airplane mode, all effectors worked conventionally.

\section{Simulation Math Model}

The longitudinal rigid aiframe aerodynamic and dynamic characteristics were modeled completely. The aerodynamic model used a component buildup method to develop total forces and moments. Momentum theory was used to calculate propeller slipstream velocities which were then used with the "power-off" aerodynamics data to obtain "power-on" aerodynamic characteristics. Other elements in the math model included coupled-wing-body equations of motion, engine and propeller dynamics, programmed flap and geared flap controls, a generic landing gear model, and a buffet boundary model. Pitch axis stabilization was augmented in rate only during the first simulation and rate plus attitude during the second simulation. The first simulation did not include a ground effects model, however the second simulation did include a developmental ground effects model. During the first simulation, the simulation model cycled real-time at a frame rate of $15 \mathrm{msec}$ on a CDC 875. During the second simulation, the simulation model cycled real-time at a frame rate of $10 \mathrm{msec}$ on a Vax 9000 .

Wing buffet is a significant issue of all tilt-wing aircraft. The buffet onset was defined from wind tunnel data and was a function of the effective wing angle-of-attack and the flap setting. The progressive deterioration of the flying qualities as deeper buffet was encountered was not modeled. A typical buffet boundary for the simulation is shown in figure 2 for a glideslope of $-7.5^{\circ}$. It should be noted that as tilt-wing aircraft transition from forward flight to hover, aerodynamic lift is replaced by powered lift and buffet onset becomes a ride quality issue. Recovery from buffet is immediate with the application of power.

The lateral/directional dynamic characteristics were modeled using stability derivatives. The dominant features were high roll damping and the addition of turn coordination above 30 knots. This study concentrated on longitudinal flying qualities, hence, accurate modeling of the lateral-directional dynamics was considered less critical to the study. A description of the math model can be found in reference 4 .

\section{Flap Control Concepts}

The programmed flap control concept uses a flap schedule that is basically a function of the wing incidence, although the pilot is provided an attenuation control. The pilot sets a desired wing incidence by using a beeper switch on the throttle grip which, in turn, sets the programmed flap deflection through cam or electrical control. The wing is directly driven by a hydraulic actuator, as shown in figure 3 .

The geared flap control concept (ref. 5) uses the flap as an aerodynamic servo tab to control the wing incidence relative to the fuselage. A schematic of this flap control concept is shown in figure 4 . The pilot input is done through a beeper switch located on the throttle grip or through a combination of the beeper switch and the longitudinal stick. Either way, the pilot input results in a flap deflection which in turn drives the wing incidence. The wing is essentially free pivoting (some damping is required) and is driven primarily by the forces generated by the flap deflections within the propeller slipstream. For example, an increase in flap deflection causes an unbalanced aerodynamic moment about the wing pivot, which is balanced when the wing rotates down canceling the moment via mechanical feedback to the flap through the wing/flap linkage. Aerodynamic moments generated by aircraft motion, friction and artificial damping also affect the pivoted wing response. 
With the programmed flap concept, the aircraft needs a tail rotor or tail thruster for pitch control in hover and at low speeds, since elevator effectiveness is not sufficient at lower velocities. Note on figure 5 that the upsetting aircraft pitching moments are caused by the thrust offset from the fuselage center of gravity as the wing tilts.

The geared flap concept, may potentially be used to eliminate the tail rotor or tail thruster (or at least to significantly reduce the pitch control power required from these auxiliary tail devices) by using the essentially freepivoting wing driven by the geared flap to provide both longitudinal and pitch control.

\section{Simulation Experiment}

\section{Simulation Facility}

Both simulations were conducted on the NASA Ames VMS. The VMS operational limits are $\pm 22 \mathrm{ft}$ of vertical motion and, depending on cab orientation, $\pm 15 \mathrm{ft}$ of longitudinal or lateral motion. Both simulations used the longitudinal orientation to focus on the longitudinal flying qualities of the aircraft. In the VMS the pilots can experience accelerations of up to $\pm 22 \mathrm{ft} / \mathrm{sec}^{2}$ vertically, $\pm 13 \mathrm{ft} / \mathrm{sec}^{2}$ longitudinally, and $\pm 10 \mathrm{ft} / \mathrm{sec}^{2}$ laterally. A sketch of the VMS is shown in figure 6.

\section{Cockpit Layout}

The same basic cockpit instruments were used for both simulations, although several instruments were arranged differently for the second simulation at the pilots' request. Glideslope and localizer information were added for the second simulation and were displayed around the attitude direction indicator (ADI). A new instrument was also added for the second simulation which combined both wing incidence and flap angle information. In addition to the analog instruments, the first simulation displayed wing incidence digitally, and the second simulation displayed both wing incidence and speed digitally. For both simulations the cockpit controls consisted of a center stick with a trim button, a left-hand throttle with a spring return rotary beep switch, rudder pedals, and a flap lever located to the left of the pilot and aft of the throttle. The flap lever was used only with the programmed flap configuration; the lever was graduated to produce $0-100 \%$ gain on the programmed flap schedule. During the first simulation, a stick shaker was installed to cue the pilot when buffet was encountered. During the second simulation, a seat shaker (no stick shaker was used) and an angle-of-attack warning light were installed to cue the pilot when buffet was encountered.

\section{Experiment Configurations}

During the first simulation, two flap control configurations, programmed flap (PF) and geared flap on the beep (GFB), were evaluated by the pilots. In the GFB configuration, the pilot controlled the geared flap using the beep switch on the throttle grip only. During the second simulation, a third flap configuration was added, geared flap on the stick (GFS). The GFS configuration allowed the pilot to control the geared flap using a combination of both the longitudinal stick and the beep switch.

All three flap configurations used the spring return rotary beep switch embedded on the throttle grip. Release of the beep switch resulted in a constant value of the last resulting wing incidence. In the PF configuration the pilot beep switch input generated a wing rate command. In the GFB configuration the pilot beep switch input generated a reference (desired) wing incidence which through the control laws resulted in a flap setting that drove the wing incidence towards the desired wing incidence. In the GFS configuration the pilot beep switch input and the longitudinal stick input were combined to generate a reference wing incidence which through the flap control resulted in the desired wing incidence. For the latter configuration the pilot had full authority of wing tilt on the beep switch and a limited authority on the longitudinal stick. The stick authority translated to about $2^{\circ}$ of wing per inch of longitudinal stick for wing incidences of $25^{\circ}-105^{\circ}$ and was gain scheduled to $0^{\circ}$ for wing incidences less than $25^{\circ}$. It should be noted that with no longitudinal stick activity, the GFB and the GFS configurations yield the same aircraft characteristics.

\section{Evaluation Tasks}

\section{First Simulation}

The evaluation tasks during the first simulation were hover station keeping, outbound transition, descending decelerating inbound transition to hover, and a short takeoff and landing (STOL) landing task.

Hover station keeping- The aircraft was positioned over a checkerboard pattern to the right of the runway at $50 \mathrm{ft}$ altitude in hover. The pilots attempted to maintain position and altitude for 3 minutes.

Outbound transition- The aircraft was positioned over a predetermined location on the runway at $50 \mathrm{ft}$ altitude in hover. The pilots smoothly increased power and ascended to $100 \mathrm{ft}$ altitude, then incrementally lowered the wing while trying to maintain altitude. The task ended at 180-200 knots and $500 \mathrm{ft}$ altitude. 
Descending decelerating inbound transition to hoverThe aircraft was positioned initially downwind of the runway at $500 \mathrm{ft}$ altitude and $12,000 \mathrm{ft}$ to the left of the runway with 200 knots velocity. The pilots slowed the aircraft velocity to about 180 knots and lowered the landing gear on the downwind leg. On the base leg, the pilots descended to $300 \mathrm{ft}$ altitude, slowed the velocity to about 100 knots and raised the wing incidence to $10^{\circ}$. On the final approach, the pilots incrementally raised the wing, adjusting power accordingly, and slowed the velocity to about 35 knots. A desired glideslope was not specified, the pilots were allowed to use whatever glideslope they preferred. As the pilots approached the hover position above the touchdown point, they descended to $50 \mathrm{ft}$ altitude and continued to raise the wing as appropriate. The task ended when the pilots brought the aircraft to a hover and landed.

STOL Landing- The aircraft was positioned initially at $500 \mathrm{ft}$ altitude and $5,000 \mathrm{ft}$ to the left of the runway with 60 knots velocity and with the landing gear down. The task ended when the aircraft landed at the target position.

\section{Second Simulation}

The evaluation tasks were redefined for the second simulation to emphasize the flying qualities differences between the control concepts during conversion and hover within the boundaries permitted by the math model (i.e., primarily longitudinal flying qualities). The baseline altitude was chosen at $70 \mathrm{ft}$ to avoid configurationspecific ground effects. The tasks were bounded by specific performance standards, thereby permitting a better application of the Cooper-Harper pilot rating method (ref. 6). The four tasks and their performance standards are described below.

Hover station keeping with turbulence- The aircraft was positioned over a predetermined location on the runway at $70 \mathrm{ft}$ altitude in hover. The turbulence level was severe at $8 \mathrm{ft} / \mathrm{sec}$ rms in all three axes. The pilot attempted to maintain position for $70 \mathrm{sec}$, using whatever technique the pilot preferred (wing incidence, pitch attitude adjustment, or a combination of the two). Desired performance was defined as $\pm 10 \mathrm{ft}$ altitude, $\pm 25 \mathrm{ft}$ longitudinal position, $\pm 25 \mathrm{ft}$ lateral position and $\pm 10^{\circ}$ heading. Adequate performance was defined as $\pm 20 \mathrm{ft}$ altitude, $\pm 50 \mathrm{ft}$ longitudinal position, $\pm 50 \mathrm{ft}$ lateral position and $\pm 15^{\circ}$ heading.

Level inbound transition to hover- The aircraft was positioned initially short of the runway threshold at $70 \mathrm{ft}$ altitude with 93 knots velocity (this initial velocity corresponded to $9^{\circ}$ wing angle in the PF configuration and to $16^{\circ}$ wing angle in the geared flap (GF) configurationsfor the same velocity, the wing angles are different because of different flap settings). The pilots decelerated the aircraft to arrive at a hover over the designated end position while trying to maintain $70 \mathrm{ft}$ altitude, level pitch attitude, and avoiding buffet. Desired performance was defined as $\pm 10 \mathrm{ft}$ for altitude, $\pm 2^{\circ}$ for pitch attitude, and less than $3 \mathrm{sec}$ total buffet time. Adequate performance was defined as $\pm 20 \mathrm{ft}$ for altitude, $\pm 4^{\circ}$ for pitch attitude, and a total buffet time greater than 3 seconds.

Descending decelerating inbound transition to hoverThe aircraft was positioned initially $6,000 \mathrm{ft}$ short of the runway at $800 \mathrm{ft}$ altitude. The initial wing incidence ( $46^{\circ}$ for $\mathrm{PF}$ and $52^{\circ}$ for GFB and GFS) was selected to yield a speed of 40 knots, hence investigating only the final stages of deceleration where buffet considerations were minimized (see fig. 2) and where differences among the control configurations were maximized. The pilots captured the $-7.5^{\circ}$ glideslope using both electronic guidance (glideslope and localizer guidance on the ADI) and the visual approach slope indicator (VASI) lights on the runway and established a nominal sink rate of $550 \mathrm{ft} / \mathrm{min}$. At $400 \mathrm{ft}$ altitude, the wing incidence was increased, and power was added as necessary to maintain flightpath. The pilots decelerated the aircraft to a hover at $70 \mathrm{ft}$ altitude while maintaining level pitch attitude and avoiding an overshoot of the designated end position. The pilots were to avoid buffet as much as possible by using low deceleration rates and by avoiding low power settings. Desired performance was defined as $\pm 1 / 2$ dot (a dot is a glideslope guidance marker on the $\mathrm{ADI}$ ) at altitudes greater than $200 \mathrm{ft}$ and \pm 1 dot at altitudes less than $200 \mathrm{ft}, \pm 2^{\circ}$ pitch attitude, no overshoot of the final hover position, and less than $5 \mathrm{sec}$ total buffet time. Adequate performance was defined as \pm 1 dot at all attitudes, $\pm 4^{\circ}$ pitch attitude, one overshoot of the final hover position, and more than $5 \mathrm{sec}$ total buffet time.

Longitudinal reposition- The aircraft was positioned initially short of the runway threshold at $70 \mathrm{ft}$ altitude in hover. The pilots began a forward translation, achieving a wing angle that was 40 deg less than the initial wing angle at hover, then started decelerating back to a hover, and ended the task in hover at $70 \mathrm{ft}$ altitude over the designated end position. The pilots were to maintain $70 \mathrm{ft}$ altitude and level attitude, avoid buffet, and arrive at the end position without overshoot. Desired performance was defined as $\pm 10 \mathrm{ft}$ altitude, $\pm 2^{\circ}$ pitch attitude, less than $3 \mathrm{sec}$ total buffet time, and no overshoot of the final hover position. Adequate performance was defined as $\pm 20 \mathrm{ft}$ altitude, $\pm 4^{\circ}$ pitch attitude, more than $3 \mathrm{sec}$ total buffet time, and one overshoot of the final hover position. 


\section{Task Environment and Visual Cues}

\section{First Simulation}

All the tasks were evaluated in daytime calm conditions and were performed visually without the aid of a flight director. No visual enhancements were added to the computer generated database.

\section{Second Simulation}

The tasks were evaluated in daytime calm conditions with the exception of the hover station-keeping task which included turbulence. The tasks were performed visually, except for the descending decelerating transition to hover, which could be performed both visually and with the aid of the glideslope and localizer information displayed on the ADI

In addition to an improved visual system, several visual cues were added to aid the pilots. VASI lights were added to help the pilots maintain glideslope. Runway cracks and tire marks were added to aid in depth perception and to add realism. Several vertical pylons consisting of stacked color-coded $10 \mathrm{ft}$ cubes were added along the edge of the runway to provide height information. STOL runway markings were superimposed over the main runway and used to define task end positions.

\section{Evaluation Pilots}

\section{First Simulation}

Nine evaluation pilots participated in the study. Six pilots had experience with fixed wing aircraft, and three had experience with helicopters. Three pilots also had experience with powered-lift aircraft; one of these pilots also had experience flying the $\mathrm{XC}-142$ tilt-wing.

\section{Second Simulation}

Six evaluation pilots participated in the study. They all had extensive experience with fixed wing aircraft and helicopters; five also had powered-lift aircraft experience. Four pilots had experience flying the XV-15 tiltrotor; one of these pilots also had experience flying the V-22 tiltrotor. One pilot also had experience flying the CL-84 tilt-wing.

\section{Results}

The flying qualities results of both simulations are summarized in figure 7 on a Cooper-Harper scale. The symbols and brackets in figure 7 indicate the mean pilot ratings and the maximum and minimum pilot ratings, respectively. The three dashed brackets in the figure indicate one pilot rating in each case that was markedly different from the other ratings (and will be discussed later). Individual task results are discussed further in this section.

During the first simulation, the pilot ratings exhibited large variations, as seen in figure 7 . This was probably due to loose constraints on task performance definitions and to different levels of pilot training.

During the second simulation, the evaluation tasks were defined more completely and desired performance standards were identified for each evaluation task. Aircraft and simulator familiarization tasks were defined and practice runs were monitored to assure that each pilot attained a similar training level. This, coupled with better instructions on general tilt-wing characteristics, led to better trained pilots; consequently, the pilot ratings exhibited less variation.

During the first simulation, pitch axis stabilization was augmented in rate only and rate plus attitude during the second simulation. Attitude augmentation was an improvement which greatly alleviated the pilot pitch-axiscontrol workload. This effect can be seen in the pitch activity in figure 8 . With the addition of pitch attitude stabilization in the second simulation, the pilots rarely reported any pitch axis control problems.

During hover, the initial response of the geared flap configurations to a forward wing command was a longitudinal aircraft acceleration transient in the rearward direction. The rearward acceleration transient is caused by a transient increase in force (lift) on the wing caused by the initial flap deflection in the propeller slipstream. Damping about the wing pivot was increased in the second simulation to reduce this adverse response. Although still noticeable to the pilots, time histories showed that the magnitudes of the rearward acceleration transients were reduced to about a third.

Pilot compensation and workload comments in this paper are based on the pilot subjective comments. Pilot performance (desired or adequate-as defined in the task definitions) during the second simulation was measured during evaluation runs. Comments on the task performance are based on actual data and not on pilot comments. 


\section{First Simulation Results}

\section{Hover Station Keeping}

Although some pilots could not detect a difference in height control between the PF and the GFB configurations, others felt that height control was less precise with the GFB configuration. With both configurations the pilots had difficulty visually holding position over the checkerboard pad and tended to drift about $50 \mathrm{ft}$ and sometimes as much as $100 \mathrm{ft}$.

\section{Outbound Transition}

The first difference noted by the pilots between the PF and the GFB configurations during this task was the initial longitudinal aircraft response to a forward wing command from the hover position. The initial response with the GFB configuration was a rearward acceleration transient which resulted in a delayed longitudinal response compared to the PF configuration.

During mid-conversion, the aircraft experienced large pitch down moments with both the PF and the GFB configurations; however, the majority of the pilots felt that the pitch down attitudes encountered with the GFB configuration were not as severe as those encountered with the PF configuration. At lower wing incidences, wing movements resulted in an aircraft heave response which was similar for both flap configurations. One pilot, who was a former XC-142 project pilot, noted that both the pitch down moments and the aircraft heave response were similar to the XC-142 aircraft behavior.

The pilot workload was associated with altitude control and with trying to minimize the pitch down attitudes encountered during mid-conversion. Pitch oscillations were sometimes encountered while trying to correct this problem. Throttle sensitivity and heave damping were low, and sometimes caused overcontrol while monitoring altitude.

\section{Descending Decelerating Inbound Transition To Hover}

The aircraft heave response to wing movements was noticed again with both configurations. At the higher wing incidences, wing movements produced less heave and more drag. Some pilots felt that the altitude changes due to the heave response were more exaggerated with the GFB configuration than with the PF configuration. Buffet was encountered with both configurations during midwing angles.
The pilot workload was associated with controlling pitch attitude, altitude and glideslope. Pilot compensation was required with power to offset the heave response to wing movements.

\section{Stol Landings}

The pilot workload was higher with the GFB configuration than with the PF configurations and was associated with trying to avoid buffet which was encountered more often with the GFB configuration. There was some initial maneuvering in altitude and velocity, but the overall approach was fairly smooth. Pilots controlled glideslope and velocity by a combination of throttle adjustments and pitch commands.

\section{Second Simulation Results}

\section{Hover Station Keeping With Turbulence}

As mentioned in the task definition, the pilots were allowed to use whatever technique they preferred (wing incidence, pitch attitude, or a combination of the two) to regulate longitudinal position in hover. With the PF configuration the majority of the pilots preferred controlling their longitudinal position with wing incidence. This preference has been noted before by CL- 84 pilots, "For forward and aft translation the pilots preferred to use wing tilt while holding the fuselage level. This was smoother, easier and more natural than tilting the whole aircraft" (ref. 7).

With both GF configurations most pilots preferred using pitch attitude over wing incidence to control longitudinal positioning. One pilot evaluated this task using both techniques and gave the pitch attitude technique a 5 and the wing incidence technique a 7 where the degradation was primarily attributed to a delay in longitudinal response leading to oscillatory longitudinal characteristics. This delay stems from a characteristic of the GF configurations mentioned earlier, where the initial response to a forward wing command results in a rearward acceleration transient. This response characteristic was also responsible for degraded speed predictability near hover with the GF configurations compared to the PF configuration.

One pilot evaluated this task with the GFB configuration on three separate runs: one with turbulence in all three axes, one with no lateral turbulence, and one with no turbulence. The pilot flying qualities ratings were 3, 2.5 and 1.5 , respectively.

One hypothesis concerning the GFS configuration was that it would reduce pitch control requirements, and hence, pitch activity might be lower than with the 
GFB configuration. However, examination of data did not show reduced pitch activity compared to the GFB configuration. This is probably due to the current level of control law development which allowed insufficient wing authority on the longitudinal stick (about $\pm 10 \%$ only).

The workload and pilot compensation associated with height and position control with both GF configurations were similar to the PF configuration, except that the lag between wing movement and perceptible longitudinal aircraft response required moderate to considerable lead compensation.

In general, the pilots achieved desired performance standards for altitude, lateral position, and heading, and adequate performance for longitudinal position. Average longitudinal drifts were $-14 \mathrm{ft}$ to $51 \mathrm{ft}$ with the PF, $-13 \mathrm{ft}$ to $38 \mathrm{ft}$ with the GFB, and $-5 \mathrm{ft}$ to $38 \mathrm{ft}$ with the GFS. In most cases the pilots were unable to perceive the longitudinal drift because of limited visual cues.

\section{Level Inbound Transition To Hover}

At low wing incidence, the short term response to wing movements was an aircraft heave response. Some pilots felt the heave response to initial wing change was reduced with the GFB configuration compared to the PF configuration; one pilot noted that the "have response to initial beep (wing tilt) was much better than (the) programmed flap, coupling (was) not as bad." Another pilot felt the throttle usage to control the heave response was lower with the GFB configurations and thus an "improvement over the programmed flap." The heave response with the GFS configuration was similar to the GFB configuration.

All pilots agreed that the time spent in buffet increased with the GFB and the GFS configurations compared to the PF configuration (an average total buffet time of $8.0 \mathrm{sec}$ for the GFB and $8.4 \mathrm{sec}$ for the GFS vs. $2.1 \mathrm{sec}$ for the PF).

Power management was required by the pilots to offset the heave response to a wing change and to avoid buffet (especially with both GF configurations). Pilot compensation was also required to predict speed towards the hover end position.

In general, the pilots achieved desired performance for altitude and pitch attitude with all three flap configurations, desired performance for buffet with the $P F$ configuration, but only adequate performance for buffet with both GF configurations.

Comments on buffet- The increased time spent in buffet with the GF configurations is most likely due to lower flap settings than the PF configuration for similar wing angles. Examination of time histories showed that buffet was encountered during the mid-wing-incidence range of $35^{\circ}-60^{\circ}$ for both the PF and the GFB configurations. During this mid-wing-incidence range, the flap range was $20^{\circ}-40^{\circ}$ for the PF and $5^{\circ}-20^{\circ}$ for the GFB.

Increase in leading and trailing edge flap deflections on the CL-84-1 improved the buffet boundary of the aircraft (ref. 8). Also, one of the methods proposed to alleviate buffet from results of flight investigations of the VZ-2 was larger flap deflections (ref. 9).

\section{Descending Decelerating Inbound Transition To Hover}

The differences among the three flap configurations were minimal during this task. Most pilots felt the workload was low because the task was slow and glideslope control required only power regulations. However, with the PF configuration, two pilots noticed a coupling between wing movement and vertical response and felt that the workload was high due to poor heave predictability. Examination of the strip charts showed that the reported heave control difficulties were associated with large abrupt wing movements.

With the GF configuration one pilot noted that he "felt glideslope tracking was the tightest so far" compared to the other two flap configurations; another pilot said "height control was easier than with the PF configuration." Since the task definition required a level pitch attitude, longitudinal stick activity was minimal, and the GFS configuration showed only subtle differences from the GFB configuration.

Largely because of the task structuring, no buffet was encountered with any of the flap configurations. In general, the pilots achieved all the desired performance standards with all three flap configurations.

\section{Longitudinal Reposition}

As noted previously, the short term response to a wing incidence change at the lower wing angles was a heave response with all flap configurations. Again, the pilots noticed that the initial longitudinal response to a forward wing command from the hover position was sluggish with both GF configurations compared to the PF configuration; hence, the resulting degraded speed predictability near hover of both GF configurations was noted by the pilots.

Using the wing incidence technique for final hover acquisition with the GFB configuration, one pilot got into a divergent position pilot induced oscillation (PIO) "that could not be suppressed with any amount of compensation" (the rating was a 7). Time histories showed that the 
flap was at the lower limit during most of the hover acquisition, which caused a distorted wing flap response.

Initially, the tail thruster pitch control power of the GFS configuration was $\pm 0.3 \mathrm{rad} / \mathrm{sec}^{2}$, which was half the pitch control power of the other two flap configurations. Several pilots evaluated this configuration without encountering any tail thruster pitch control power limits. However, one pilot, using an aggressive wing tilting technique, did encounter loss of aircraft control because of tail thruster control power saturation, “....an overshoot was developing which required continuous wing beep (wing movement). As power was increased to account for the loss of wing lift, the power-pitch coupling response became apparent and objectionable. It was countered with stick input but when the flaps reached the deflection limit a divergent pitch PIO rapidly developed that resulted in loss of control after two oscillations." This resulted in the flying qualities rating of 10 . The tail thruster pitch control power of the GFS configuration was increased to $\pm 0.6 \mathrm{rad} / \mathrm{sec}^{2}$ (the same as the other two configurations), and the problem did not occur again. The same pilot using the same aggressive wing tilting technique evaluated the task again and the rating was a 5 .

Pilot compensation was required to lead the heave response with throttle and to predict speed towards the end of the task. The workload was primarily in the vertical axis trying to maintain altitude. One pilot noted that, "...conditions were ideal and that any complications due to wind, turbulence or visibility would significantly add to the workload."

In general, with the PF configuration the pilots achieved all the desired performance standards. With both GF configurations, the pilots achieved desired performance standards for altitude and buffet, and desired to adequate performance for pitch attitude.

\section{Tail Thruster Pitch Control Power Usage}

The maximum tail thruster pitch control power was $0.6 \mathrm{rad} / \mathrm{sec}^{2}$ for both the PF and the GFB configurations. As previously discussed, the maximum pitch control power of the GFS configuration was initially $0.3 \mathrm{rad} / \mathrm{sec}^{2}$, and was later increased to $0.6 \mathrm{rad} / \mathrm{sec}^{2}$. The V/STOL Handling Qualities Criteria (ref. 10) recommends that available pitch control power be in the range of $0.4-0.8 \mathrm{rad} / \mathrm{sec}^{2}$ in hover and $0.4-0.6 \mathrm{rad} / \mathrm{sec}^{2}$ STOL mode.

The following discussion on pitch control power usage refers to results obtained during the second simulation only. The pitch control power commanded is a result of the pilot's longitudinal stick input and the SAS (stability augmentation system) input. The longitudinal stick input to tail thruster command logic was the same for each of the three configurations. The SAS input was added to the longitudinal stick input, and the combined pitch control power was limited to $0.6 \mathrm{rad} / \mathrm{sec}^{2}$. The tail thruster was not phased out at the higher velocities.

The maximum pitch control power used during all runs evaluated for each task is summarized in table 1 . For the hover case, the maximum pitch control power used with the $\mathrm{PF}$ and the GFB configurations is broken down according to pilot longitudinal positioning technique (i.e., wing or stick).

Table 1. Maximum pitch control power encountered $\left(\mathrm{rad} / \mathrm{sec}^{2}\right)$

\begin{tabular}{lccc}
\hline \hline & $\begin{array}{c}\text { Longitudinal } \\
\text { reposition }\end{array}$ & $\begin{array}{c}\text { Level } \\
\text { inbound }\end{array}$ & $\begin{array}{c}\text { Descending } \\
\text { decelerating }\end{array}$ \\
\hline PF & 0.24 & 0.18 & 0.13 \\
GFB & 0.34 & 0.36 & 0.18 \\
GFS & 0.34 & 0.31 & 0.22 \\
\hline \multicolumn{3}{c}{ Hover in turbulence } \\
\hline PF (wing) & 0.18 \\
PF (stick) & 0.26 \\
GFB (wing) & 0.22 \\
GFB (stick) & & 0.14 \\
GFS (wing \\
and stick)
\end{tabular}

It is important to note that in most cases the maximum pitch control power encountered was an isolated "spike" in the data, often resulting from aggressive wing tilting. This occurred especially in the case of the geared flap configurations where aggressive wing tilting drove the flap into a position limit $\left(0^{\circ}\right.$ if tilting up or $60^{\circ}$ if tilting down) which then resulted in a large spike increase in pitch control power. Aggressive wing tilting also increased the pitch control power usage of the programmed flap, but because the programmed flap was scheduled, flap position limits were never encountered and the increases in pitch control power were not as large as with the geared flap. 
Comparison of the values shown in table 1 does not show a reduction in pitch control power used by the geared flap configurations compared to the programmed flap configuration. However, the values in table 1 are pitch control power results of the flap concepts at the current stage in development. Further control law development and more study on the treatment of flap stops and wing pivot location are needed to address the pitch control power issue.

\section{Summary of Results}

1. The pilot ratings and comments showed that in general, the programmed flap and the two geared flap configurations had similar flying qualities (in the level 1-2 range). Hence, the geared flap concept is feasible for tilt-wing aircraft.

2. Two main differences between the programmed flap and the geared flap configurations were the amount of time spent in buffet and the longitudinal aircraft response in hover. The amount of time spent in buffet was greater with both geared flap configurations than with the programmed flap configuration because of lower flap deflections for similar wing incidences. With both geared flap configurations, the initial longitudinal aircraft response to a forward wing command from hover was a rearward acceleration transient. This acceleration transient resulted in sluggish longitudinal aircraft response and hence in degraded speed predictability near hover with both geared flap configurations compared to the programmed flap configuration. The transient response was reduced in the second simulation with the addition of damping about the wing pivot.

3. The pitch attitude stability augmentation system (SAS) added to the flap configurations during the second simulation was a significant improvement over the pitch rate SAS of the first simulation, and greatly alleviated the pilot workload associated with pitch axis control.

4. At the current level of development the results did not show a reduction in tail thruster pitch control power usage for the geared flap configurations compared to the programmed flap configuration.

\section{References}

1. Guerrero, L. M.; and Corliss, L. D.: Handling Qualities Results of an Initial Geared Flap Tilt Wing Piloted Simulation. SAE Paper 911201 , Apr. 1991.

2. Guerrero, L. M.; and Corliss, L. D.: Initial Piloted Simulation Study of Geared Flap Control for Tilt-Wing V/STOL Aircraft. NASA TM-103872, Oct. 1991.

3. Birckelbaw, L. G.; and Corliss, L. D.: Phase II Simulation Evaluation of the Flying Qualities of Two Tilt-Wing Flap Control Concepts. SAE Paper 920988, Apr. 1992.

4. Totah, J.: Description of a Tilt Wing Mathematical Model for Piloted Simulation. Presented at the 47th Annual Forum of the American Helicopter Society, Phoenix, Arizona, May 1991.

5. Churchill, G.: Evaluation of Geared Flap Control System for Tiltwing V/STOL Aircraft. Boeing Report No. D8-2076, AD 712 645, Jan. 1969.

6. Cooper, G. E.; and Harper, R. P., Jr.: The Use of Pilot Rating in the Evaluation of Aircraft Handling Qualities. NASA TN D-5153, Apr. 1969.

7. Bernstein, S.: CL-84 Tilt Wing Applications. The Sixth Congress of the International Council of the Aeronautical Sciences Paper No. 68-45, Sept. 1968.

8. Phillips, F. C.: The Canadair CL-84 Experimental Aircraft Lessons Leamed. AIAA Paper 90-3205, Sept. 1990.

9. Pegg, R. J.; Kelley, H. L.; and Reeder, J. P.: Flight Investigations of the VZ-2 Tilt-Wing Aircraft With Full-Span Flap. NASA TN D-2680, March 1965.

10. Anon: V/STOL Handling Qualities Criteria I Criteria and Discussion. North Atlantic Treaty Organization, Advisory Group for Aeronautical Research Development. Report no. 577, part I, Dec. 1970. 


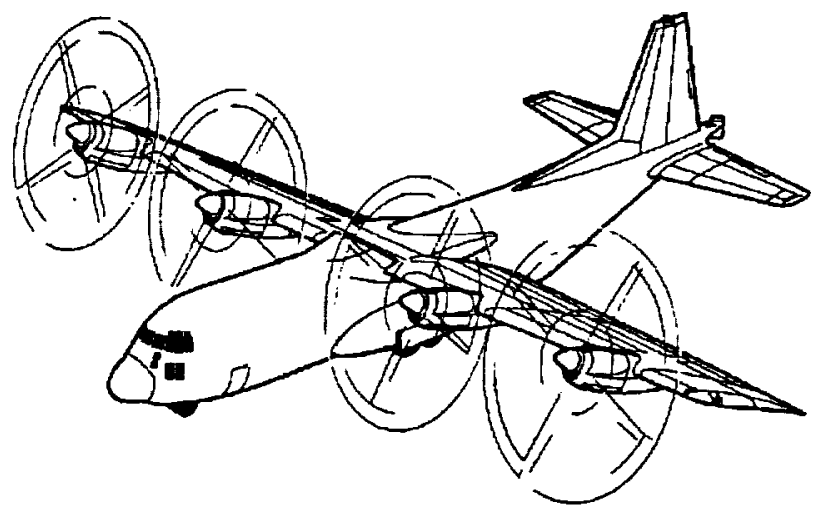

Figure 1. Simulate tilt-wing aircraft.

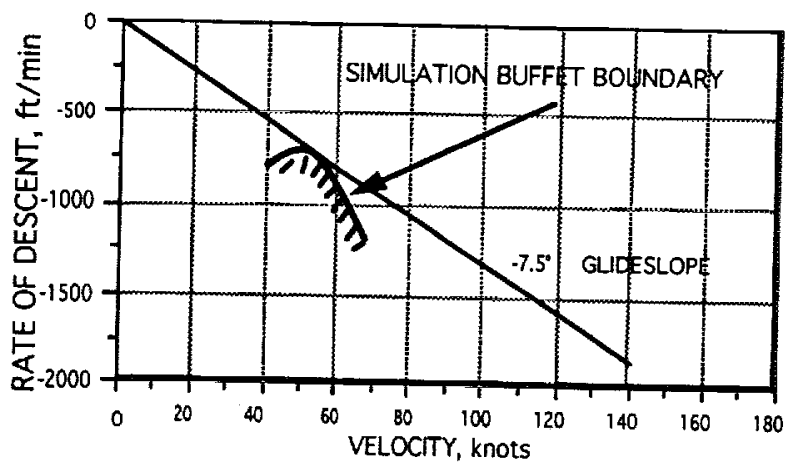

Figure 2. Simulation buffet boundary for $-75 \%$ glideslope.

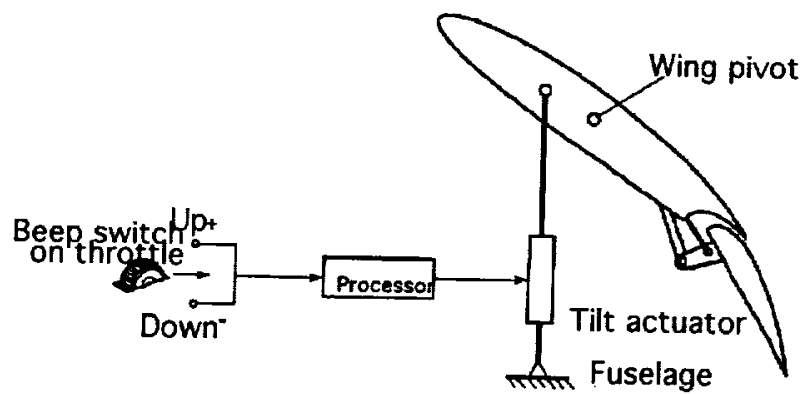

Figure 3. Programmed flap control concept.

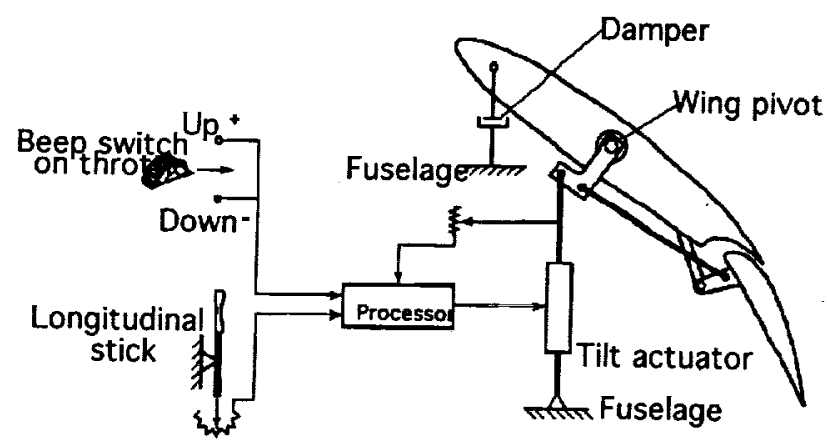

Figure 4. Geared flap control concept.

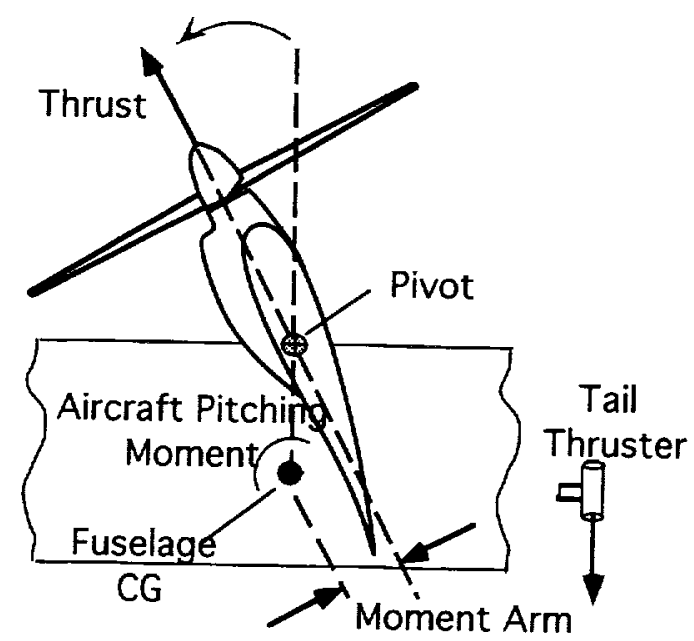

Figure 5. Tilt-wing pitching moments due to wing rotation.

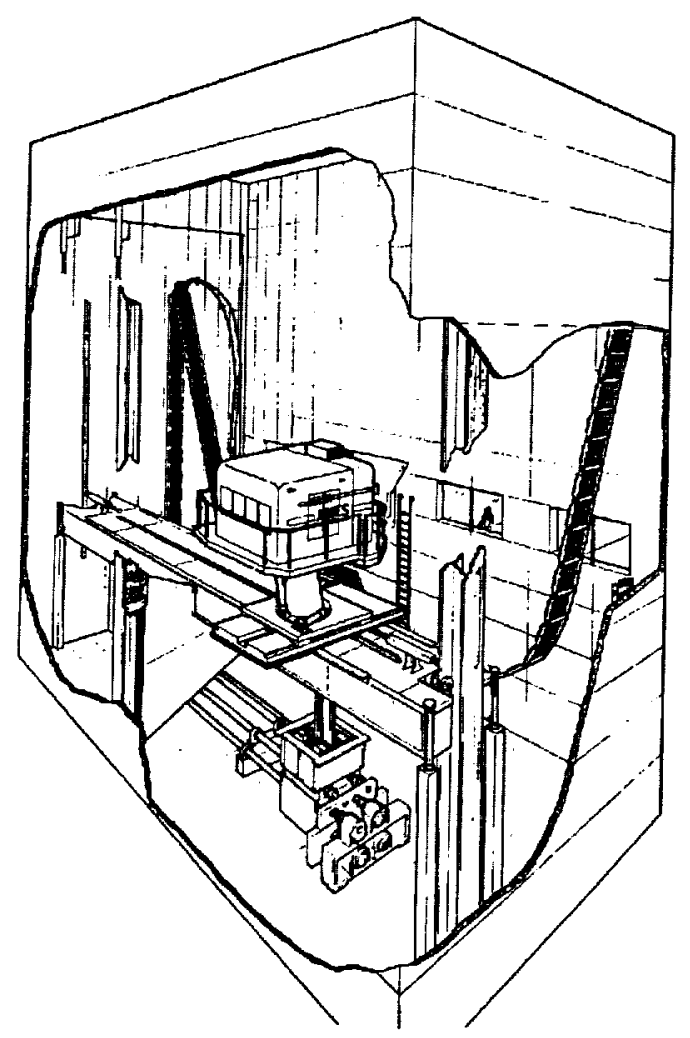

Figure 6. Vertical motion simulator. 


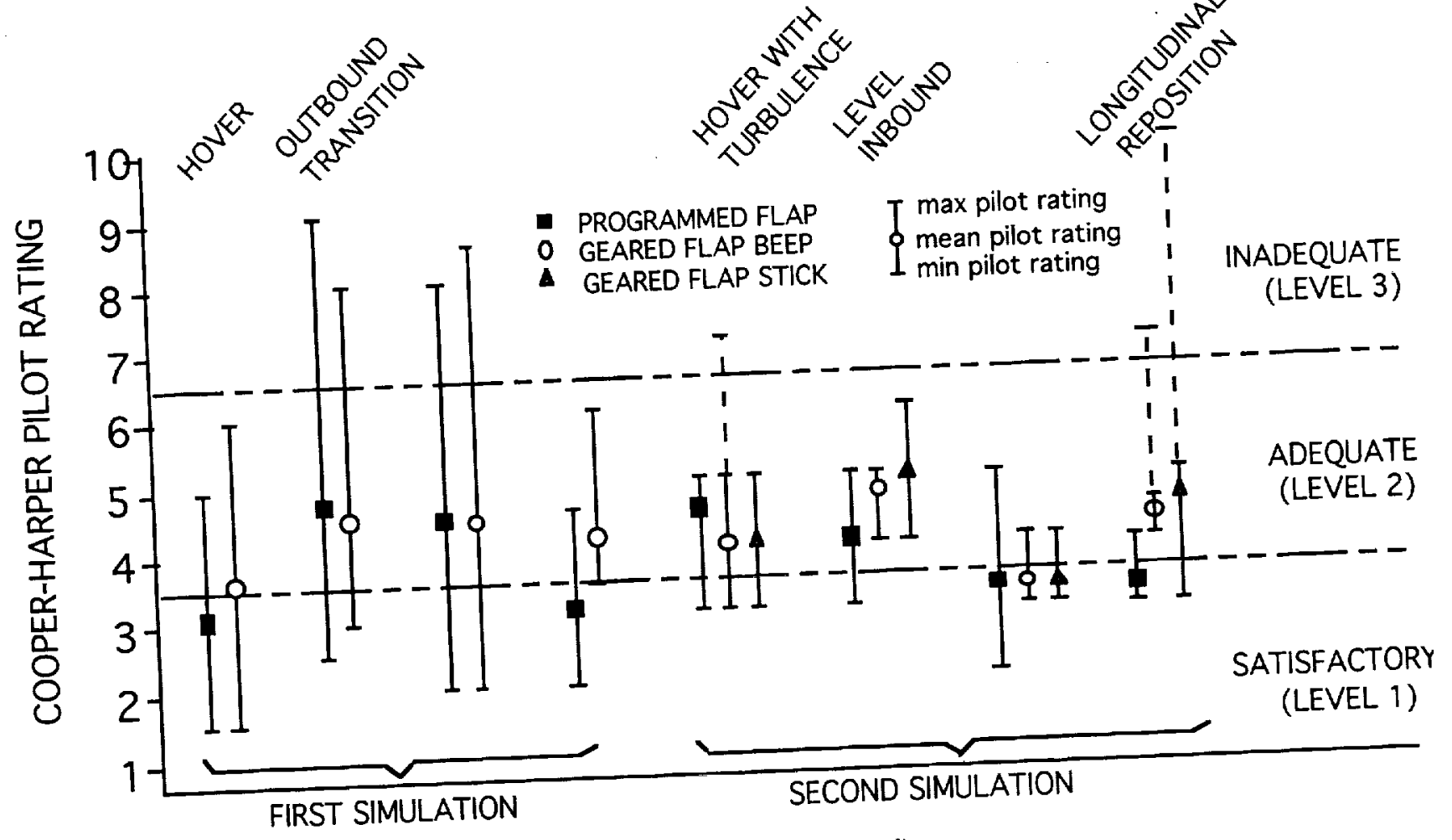

Figure 7. Flying qualities results.
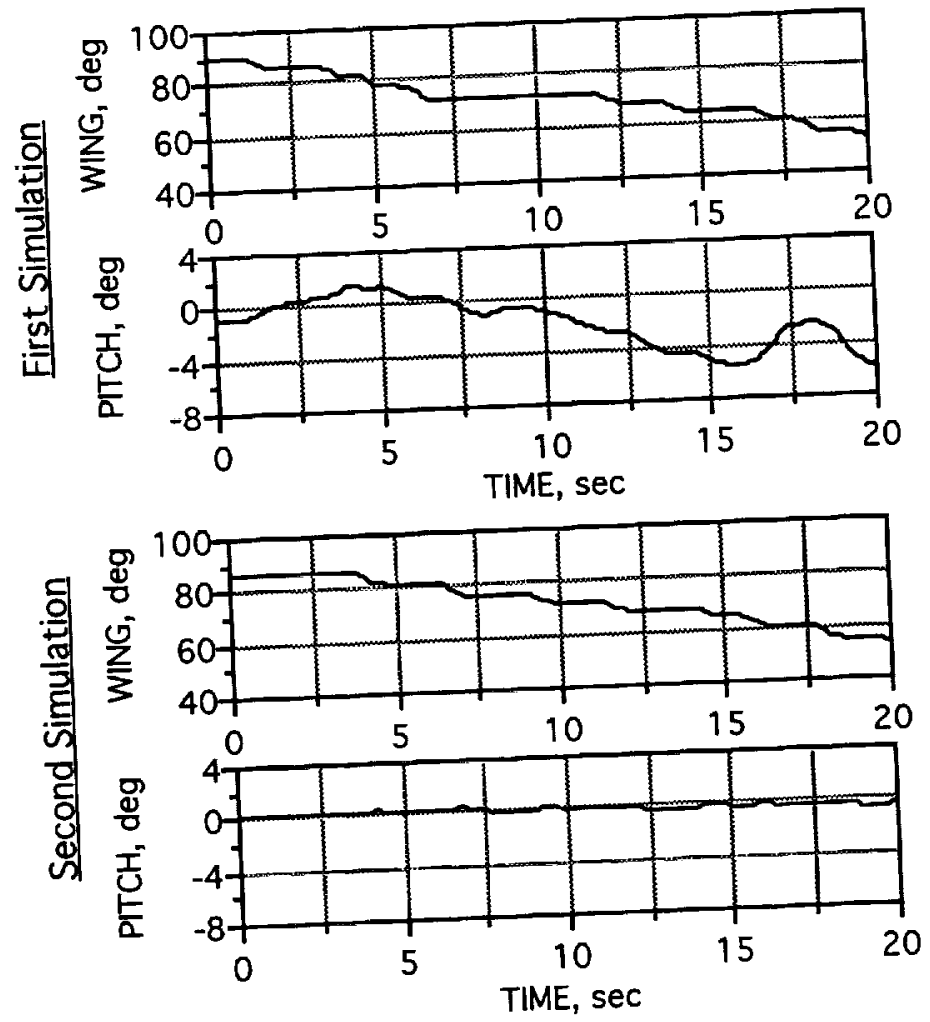

Figure 8 . Time histories before and after pitch attitude stabilization. 


\section{Biography}

Lourdes G. Birckelbaw has been working at NASA Ames Research Center since 1989. She is currently working in the STOVL/Powered-Lift Technology Branch where she of ski jump involved in the piloted simulation evaluation STOVL aircraf short takeoff performance of a supersonic researcher in the Ames piloted she has been a key wing/flap controls for piloted simulation study of received a B. S. in Aerospace E/STOL aircraft. She Institute of Technology in 1983, afteering from Georgia cooperative education program for two years with Lockheed Aeronautical Systems Company. She received her M.S. in Aerospace Engineering from Georgia Tech. in 1986. From 1983-1989, she worked at Lockheed Aeronautical Systems Company including two years in the Flight Simulations Group and four years in the Flight Controls Group.

Lloyd D. Corliss is presently in charge of flight controls for the NASA Ames Military Technology Office. He earned a B.S (1963) and an M.S. (1966) in Electrical Engineering from Michigan State University, and has completed post-graduate studies in Aeronautics at Stanford University. He was formerly with the US Army Research Technology Lab at Moffett Field, CA, where he served as flight controls project engineer for the development of several digital flight control systems on both VTOL and helicopter experimental test bed aircraft. Mr. Corliss has conducted numerous simulation and flight test studies in the area of controls and flying qualities, and he has authored over 25 technical publications. Mr. Corliss was the recipient in 1983 of the Department of the Army R\&D Achievement Award and is a Professional Engineer.

Ms. Birckelbaw and Mr. Corliss are recipients of the 1991 Wright Brothers Medal awarded by SAE to the authors of the best paper relating to the invention, development, design, or operation of an aircraft or spacecraft. The award winning paper was titled "Handling Qualities Results of an Initial Geared Flap Tilt Wing Piloted Simulation" (SAE 911201). 